NBER WORKING PAPER SERIES

\title{
THE EFFECT OF MEDICARE COVERAGE FOR THE DISABLED ON THE MARKET FOR PRIVATE INSURANCE
}

\author{
John F. Cogan \\ R. Glenn Hubbard \\ Daniel P. Kessler \\ Working Paper 14309 \\ http://www.nber.org/papers/w14309 \\ NATIONAL BUREAU OF ECONOMIC RESEARCH \\ 1050 Massachusetts Avenue \\ Cambridge, MA 02138 \\ September 2008
}

Respectively, Leonard and Shirley Ely Senior Fellow, Hoover Institution, Stanford University; Dean and Russell L. Carson Professor of Finance and Economics (Graduate School of Business) and Professor of Economics, Columbia University, and Research Associate, National Bureau of Economic Research; and David S. and Ann M. Barlow Professor in Management (Graduate School of Business) and Senior Fellow (Hoover Institution), Stanford University, and Research Associate, National Bureau of Economic Research. We would like to thank Jay Bhattacharya for the suggestion of using the PSID and Alan Auerbach, Kate Bundorf, Jonathan Skinner, and participants at the NBER Summer Institute for helpful comments. Kessler gratefully acknowledges funding from the National Institutes on Aging. The views expressed herein are those of the author(s) and do not necessarily reflect the views of the National Bureau of Economic Research.

NBER working papers are circulated for discussion and comment purposes. They have not been peerreviewed or been subject to the review by the NBER Board of Directors that accompanies official NBER publications.

(C) 2008 by John F. Cogan, R. Glenn Hubbard, and Daniel P. Kessler. All rights reserved. Short sections of text, not to exceed two paragraphs, may be quoted without explicit permission provided that full credit, including $\odot$ notice, is given to the source. 
The Effect of Medicare Coverage for the Disabled on the Market for Private Insurance John F. Cogan, R. Glenn Hubbard, and Daniel P. Kessler

NBER Working Paper No. 14309

September 2008, Revised February 2010

JEL No. I1

\begin{abstract}
$\underline{\text { ABSTRACT }}$
Subsidies for health insurance for chronically ill, high-cost individuals may increase coverage in the broader population by improving the functioning of insurance markets. In this paper, we assess an historical example of a policy intervention of this sort, the extension of Medicare to the disabled, on the private insurance coverage of non-disabled individuals. We use data on insurance coverage from the Panel Study of Income Dynamics from before and after the extension of Medicare to the disabled to estimate the effect of the program on private insurance coverage rates in the broader population. We find that the insurance coverage of individuals who had a health condition that limited their ability to work increased significantly in states with high versus low rates of disability. Our findings suggest that that subsidizing individuals with high expected health costs is an effective way to increase the private insurance coverage of other high-cost individuals.
\end{abstract}

John F. Cogan

Hoover Institution

Stanford University

Stanford, CA 94305

cogan@hoover.stanford.edu

R. Glenn Hubbard

Graduate School of Business

Columbia University, 101 Uris Hall

3022 Broadway

New York, NY 10027

and NBER

rgh1@columbia.edu,ws2187@columbia.edu
Daniel P. Kessler

Graduate School of Business

Stanford University

518 Memorial Way, Room L241

Stanford, CA 94305

and NBER

fkessler@stanford.edu 


\section{INTRODUCTION}

Does the removal of high-cost individuals from private insurance markets lead to greater coverage for individuals who are similar but not as high cost? In theory, if removing high-cost individuals reduces the range of hidden information in insurance markets, then it will dampen insurers' incentives to protect themselves against adverse selection. As incentives to protect against adverse selection decline, pooling increases, which benefits the high-cost individuals who remain (Newhouse, 1996).

The answer to this question is central to current health policy debates. Subsidies for insurance for the chronically ill, for example, seek to provide high-cost individuals with coverage at something like a community rate, but without forcing low-cost individuals to finance the cost through their purchase of insurance (Swartz, 2003; Holahan, et al., 2003). The general equilibrium effect of these subsidies, however, depends on how they affect the form and extent of coverage in the broader insurance market. Yet, despite this, there is little empirical evidence how such policies might perform.

In this paper, we assess an historical example of a policy intervention of this sort, the extension of Medicare to the disabled, on the private insurance coverage of nondisabled individuals. In 1973, Congress extended Medicare benefits to beneficiaries of the Social Security Disability Insurance (SSDI) program; prior to then, there was no uniform, comprehensive public insurance program for the disabled. More important for the purposes of our study, extending Medicare to the disabled also had the effect of removing high-cost individuals from the broader pool of the privately insured. 
No empirical evidence exists of the impact of this policy, or similar policies, on the private insurance coverage of non-disabled individuals. We use data on insurance coverage from the Panel Study of Income Dynamics (PSID) from before and after the extension of Medicare to the disabled to estimate the effect of the program on private insurance coverage rates in the broader population. We find that the insurance coverage of individuals who had a health condition that limited their ability to work increased significantly in states with high versus low rates of SSDI beneficiaries. These "worklimited" individuals included, but were not limited to, SSDI beneficiaries. The increase in the number of work-limited individuals with insurance was far greater than the number of Medicare eligibles. Thus, the expansion of Medicare not only increased coverage among the targeted population of the disabled, but also among people who were similarly situated but less seriously impaired, suggesting the potential usefulness of subsidies to high-cost individuals in promoting insurance coverage generally.

Then, we use data from the Health Insurance Council ${ }^{1}$ from 1970-1980 to estimate the effect of the extension of Medicare on private insurance comprehensiveness. As we discuss below, the same model that predicts that the extension of Medicare could have spillover effects also predicts that it could lead to increases in the comprehensiveness of coverage. We find that the comprehensiveness of private health insurance increased significantly after versus before the extension of Medicare in states with high versus low rates of SSDI beneficiaries.

Our analysis proceeds in the next five sections. Section II presents a theoretical framework that explains how targeted subsidies for health insurance can have effects in

\footnotetext{
${ }^{1}$ The Health Insurance Council became the Health Insurance Association of America, which later became America's Health Insurance Plans.
} 
the broader population. In section III we discuss the data we use for our analysis, describe our methodological approach, and present tabular results which show evidence of a large impact of the extension of Medicare on non-disabled coverage rates. We embed this analysis in a more general econometric model in Section IV and present results. In section $\mathrm{V}$, we estimate the effect of the extension of Medicare on the scope of the policy offerings of private insurers. Section VI concludes.

\section{THEORETICAL FRAMEWORK}

The canonical Rothschild-Stiglitz (1976) model of insurance markets has two key predictions: heterogeneous individuals can not exist in the same insurance plan, and high-cost individuals obtain the insurance they most prefer. In this model, subsidies to high-cost individuals have no effect on anyone other than the targeted group. Yet, in practice, the stark predictions of Rothschild-Stiglitz do not occur. In general, it is highcost individuals (not low-cost individuals) who have greater difficulty obtaining their desired level of insurance. This suggests that the canonical model may be a poor tool for predicting the consequences of targeted subsidies.

Joseph Newhouse (1996) shows how extending Rothschild-Stiglitz to include contracting costs makes the model more realistic. In Newhouse's model, fixed costs to writing separate types of insurance policies can make it profitable to offer a policy that both high- and low-cost individuals will buy. If these fixed costs are large enough, then it will not pay for an insurer to move from a pooling equilibrium to one that segregates the two types. 
The Newhouse model also generates several intuitive comparative static results. First, increases in the transaction costs of writing separate contracts or, equivalently, decreases in the range of types in the market leads to increases in the extent of pooling. Greater pooling, in turn, means lower premiums and higher coverage rates for high-cost individuals. Second, decreases in the range of types in the market increases the comprehensiveness of insurance policies that are offered in equilibrium. Transactioncost induced pooling constrains the generosity of plans that can be profitably offered, because low-cost individuals prefer less than full insurance; but as the types become more similar (holding transaction costs constant) the scope of insurance that will support pooling increases.

Targeted subsidies have the effect of decreasing the effective range of types in the market, either by offsetting the expected medical expenses of high-cost individuals or by removing such individuals from the market entirely. Thus, subsidies may have spillover effects on those who are untargeted but similar. In this paper, we test this prediction: whether the extension of Medicare to the disabled increased the coverage of nondisabled individuals with high expected costs and increased the scope of health insurance offered in the market. To date, no work has provided empirical evidence of such a scheme's incentives. This paper seeks to fill this gap. We examine a "natural experiment" from the recent past — the extension of Medicare in 1973 to disabled individuals receiving SSDI. This policy had the effect of removing individuals with high expected health costs from private health insurance pools. We estimate the impact of this policy on the coverage of both the population at large and a high-cost segment of the population who was at risk of becoming, but had not yet necessarily become, disabled — individuals who 
are limited in the kind or amount of work they can do ("work-limited" individuals). We compare trends in coverage of these individuals before versus after the extension of Medicare in states with large versus small SSDI populations. In so doing, we can assess the potential effectiveness of subsidization of high-cost individuals as a policy to improve the functioning of private markets.

\section{DATA AND ESTIMATION APPROACH}

\section{A. Data}

To identify health insurance coverage rates, we use data from the Panel Study of Income Dynamics (PSID), waves 2-5 and 13 (that is, 1969-1972 and 1980). ${ }^{2}$ In each of these years, the PSID asked heads of household whether they were "covered by some hospital or medical insurance, like Blue Cross" except in 1980, when it asked whether they were "covered by some hospital or medical insurance, like Medicare, Blue Cross, or Blue Shield." (The health insurance question was not asked in any year 1973-1979.) Our sample is limited to persons age 64 or less, and we omitted all individuals whose response to this question was missing. In each of these years, the PSID also asked heads of household whether they had a "physical or nervous condition that limits the kind or amount of work" they could do. In 1980, 15.7 percent of the population answered yes to

\footnotetext{
${ }^{2}$ The PSID is a longitudinal survey of a representative sample of U.S. individuals and their families, started in 1968. Data are collected annually, and the data files contain the full span of information collected over the course of the study. The study's original households constitute a national probability sample of U.S. households as of 1967. Its rules for following household members were designed to maintain a representative sample of families at any point in time as well as across time. The most detailed information is collected each year about the heads of family units. Around the time that Medicare was extended to the disabled, data on health insurance was asked only of heads, and only in 1969, 1970, 1971, 1972, and 1980.
} 
this question (in all years, 16.1 percent answered yes); we classify these individuals as "work-limited" in our subsequent analysis.

Ideally, to measure each state's density of high-cost individuals who would be removed from the private insurance market by the extension of Medicare, we would use the number of nonelderly SSDI beneficiaries who would be eligible for Medicare per nonelderly resident. However, only the total number of nonelderly SSDI beneficiaries per nonelderly resident is available. Because the latter includes individuals who have been on SSDI for less than 29 months (and therefore are not eligible for Medicare), the former is a more accurate measure of the differential impact across states of the extension of Medicare to the disabled. However, if anything, our use of an imperfect proxy in this context is likely to lead us to understate the effect of interest. If the number of SSDI beneficiaries who would be eligible for Medicare were a proportion of the total that was constant across states, then our estimate would understate the true magnitude by the inverse of this proportion. (If the number of SSDI beneficiaries who would be eligible for Medicare were a proportion of the total that was random across states, this would further bias our estimate towards zero.) Our stratification of states would only bias us in favor of finding an effect if states with expanding private insurance markets also had an expanding proportion of SSDI beneficiaries who would be eligible for Medicare.

We also matched data on the number of nonelderly Medicaid beneficiaries by state for the years 1969, 1972, and 1980 (we calculated data for years 1970 and 1971 by linear interpolation). We divided the number of Medicaid beneficiaries by each state's nonelderly populaton to get state Medicaid enrollment rates. We control for Medicaid enrollment rates in estimating the effect of the extension of Medicare for two reasons. 
First, and most important, the survey question underlying our dependent variable is ambiguously worded. Ostensibly, the question was intended to measure private insurance coverage, but could be interpreted to include coverage by Medicaid. Because we are seeking to identify the effect of the extension of Medicare on private coverage, not private plus Medicaid coverage, we include Medicaid enrollment as a control variable. Second, even if the survey question measured only private insurance coverage, the endogeneity of state Medicaid policies, combined with Medicaid crowd-out, could lead to correlation between the number of SSDI beneficiaries and private insurance coverage. This result could occur, for example, if Medicaid enrollment is positively related to a state's disability rate, and increases in Medicaid lead to decreases in private insurance coverage.

Table 1 presents descriptive statistics on the PSID population that we analyze. The first row of the table shows that most nonelderly heads of household are covered by insurance and that this share remained roughly constant over our study period. The second row shows that, according to the PSID, roughly 16 percent of the population report themselves to be work-limited, and that this share too remained roughly constant over the 1970 s.

Table 2 shows how we classify states based on their rates of SSDI receipt. We coded a state as "high disability" if its disability rate in a given year was above the population-weighted median; we coded it as "low disability" if its disability rate was below the median. The first row contains the list of states in each study year that have above the population-weighted median level of SSDI. The remaining rows provide the median SSDI rate, the 25 th -75 th interquartile range of SSDI rates, and the average SSDI 
rates in high- and low- disability states. In 1980, for example, the median rate of SSDI receipt was 1.37 percent (based on the interquartile range of $1.21,1.52$ percent).

\section{B. The Effect of Medicare for the Disabled on Private Insurance Coverage Rates}

Figure 1 presents the basic results of our analysis. Figure 1 contains four lines, each representing the trend in coverage rates over the 1969-80 period for one of four types of individuals. The top line presents coverage for individuals from a low disabilitystate who were not work-limited; directly below it is the line for individuals from a highdisability state who were not work-limited. Insurance coverage rates follow the pattern that the Newhouse model would predict. When there is partial pooling, areas with a disproportionate number of high-cost individuals have lower coverage overall. The bottom two lines present coverage rates for work-limited individuals from low- and highdisability states, respectively. Consistent with pooling being only partial, work-limited individuals have lower coverage rates overall. The striking feature of this graph, however, is the discontinuity in coverage rates for work-limited individuals from highdisability states, which rose dramatically by 1980 , after the extension of Medicare.

Table 3 presents these same results in tabular form with standard errors allowing for arbitrary correlation of coverage rates across individuals within a state over time. ${ }^{3}$ The top panel of the table presents coverage rates for respondents who were not worklimited; the bottom panel presents the same data for those who were work-limited. The top panel shows that the insurance coverage rate for heads of household who were not work-limited fell by 2.3 percentage points less in high- versus low-disability states, although the difference is not statistically significant. The coverage rate in high-

\footnotetext{
${ }^{3}$ Bertrand, Duflo, and Mullainathan (2004) show that the standard errors of difference-in-difference estimators assuming independence of individual observations are, in general, inconsistent.
} 
disability states declined by 0.3 percentage points, while the coverage rate in lowdisability states declined by 2.6 percentage points. The difference in trends in coverage between these two types of states is the difference-in-difference (DD) estimator of the effect of the expansion of Medicare.

The bottom panel of the table presents the same coverage rates for respondents who were work-limited. The effect of Medicare's expansion on this population is far more dramatic: The coverage rate in high-disability states rose by 20.2 percentage points, from 57.7 to 77.9 percent. The coverage rate in low-disability states rose also, but by only 1.7 percentage points. For work-limited individuals, then, the DD estimator of the effect of the expansion of Medicare is 18.5 percentage points (with a heteroscedasticity-consistent standard error allowing for within-state correlation of residuals of 4.5 percentage points).

The final rows of the table present the difference between these two DD estimates — that is, the difference in trends in coverage for work-limited versus not work-limited individuals in high- versus low-disability states. This difference-in-difference-indifference (DDD) estimator of the effect of Medicare is 16.2 percentage points (with a standard error of 3.6 percentage points). The DDD estimator is more conservative than the DD estimator on the work-limited population. The DDD estimate assumes that the difference in trend coverage between high- and low-disability states for not work-limited individuals was not due to the change in Medicare coverage policy.

The DDD estimate of the increase in coverage due to the extension of Medicare is much larger than number of people actually covered by the program itself. In 1980, the average SSDI rate (population weighted according to the PSID) in high-disability states 
was 1.7 percentage points, as compared to an average in low-disability states of 1.2 percentage points (not in any table). According to the simple DDD estimate, then, the 0.5 percentage point of additional coverage offered by Medicare's expansion led to a total of 2.5 percentage points of additional insurance coverage $(0.025=0.162$ percentage point increase in coverage* 0.157 of population that was work-limited in 1980). In other words, the extension of Medicare to the disabled led to 2 percentage points $(0.02=0.025$ $0.005)$ of additional private insurance coverage.

These simple estimates, however, do not account for time-varying differences across states that may be correlated with differences in disability and private insurance coverage rates. For example, state Medicaid enrollment rates may have changed across states during this period due to changes in state-specific eligibility rules or other Medicaid policies. Alternatively, the differential increase in coverage of the worklimited in high-disability states could be due to differences in trends in macroeconomic factors at the state or regional level. Finally, the observed coverage effects could be due to changes in the composition of individuals or jobs, or the labor- or insurance-market opportunities of particular types of individuals, in high- versus low-disability states.

\section{IV.ECONOMETRIC MODELS AND RESULTS}

\section{A. Models}

To explore these possibilities, we specify a model of insurance coverage. We analyze individual heads of household $i=1, \ldots, \mathrm{N}$ in states $j=1, \ldots, 50$ for the years $t=$ 1969, 1970, 1971, 1972, 1980. An individual has characteristics $X_{i j t}$ that include age, gender, race, veteran status, family size, family income, education, occupation, whether 
self-employed, and whether out of the labor force. We define age as a series of indicator variables denoting whether the individual is age $25-34$, age $35-44$, age $45-54$, or age 5564 (age 15-24 is the omitted group). We define family income as two indicator variables, one for families with incomes between $\$ 8,000$ and $\$ 24,999$ (in 1980 dollars), and one for families with incomes greater than $\$ 24,999$ (income less than $\$ 8,000$ is omitted group). We define educational attainment as a series of indicator variables denoting whether the individual is high-school-educated, has some college education, or is a college graduate (less-than high school education is the omitted group); occupation is an indicator variable for whether the policyholder is a professional or technical worker (all other occupations are the omitted group). We use the variable $W_{i j t}$ to capture whether an individual is worklimited.

Our models specify insurance coverage, $C_{i j t}$, as a function of state fixed effects, $\alpha_{j}$, and time fixed effects, $\theta_{t}$; state Medicaid enrollment rates and average income, $M_{j t}$; the characteristics of individuals, $X_{i j t}$ and $W_{i j t}$; a variable capturing the state's SSDI enrollment rate, $D_{j t}$; interactions between $D_{j t}, W_{i j t}$, and an indicator for 1980 (the only study period after the extension of Medicare); and an individual-specific error term $\varepsilon_{i j t}$ :

$$
\begin{aligned}
& C_{i j t}=\alpha_{j}+\theta_{t}+\delta M_{j t}+X_{i j t} \beta+W_{i j t} \gamma+\pi_{1} D_{j t}+\pi_{2}\left(D_{j t} * W_{i j t}\right)+ \\
& \quad \pi_{3}\left(W_{i j t} * I_{t}(t=1980)\right)+\pi_{4}\left(D_{j t} * I_{t}(t=1980)\right)+\pi_{5}\left(D_{j t} * W_{i j t} * I_{t}(t=1980)\right)+\varepsilon_{i j t} .
\end{aligned}
$$

The coefficient $\pi_{5}$ is the DDD effect of the extension of Medicare - that is, the differential trend in coverage in high- versus low-disability states, for work-limited individuals relative to those who are not work-limited.

\section{B. Results}


Table 4 reports estimates of $\pi, \gamma$, and $\delta$ from equation (1). The results show that the simple DD and DDD estimators from Table 3 present an accurate portrait of the effect of the expansion of Medicare. Results in column (2) show that moving from a low- to a high-disability state leads to a 13.3 percentage point increase in the coverage of worklimited versus not work-limited individuals (with a standard error of 3.6 percentage points), controlling for state and year fixed effects, the state's Medicaid coverage rate and average income, and a variety of individual characteristics. Comparing column (1) to column (2) shows that the results are not sensitive to the inclusion of individual characteristics $X_{i j t}$. We also re-estimated models (1) and (2) without controls for state Medicaid enrollment rates; this did not change the results at all.

The results in column (4) show that the estimated effect declines in a linear specification, but it remains economically and statistically significant. According to that model, an increase in the state SSDI rate of 0.5 percentage-point leads to a 7.8 $(=0.5 * 15.7)$ percentage point increase in the coverage of work-limited versus not worklimited individuals (standard error 3 percentage points). By comparison, the results in column (2) suggest that an increase in the state SSDI rate of 0.5 percentage points from 1.2 to 1.7 percentage points leads to a 13.3 percentage point increase in the trend in relative coverage rates.

\section{Validity checks}

To investigate the validity of these results, we reestimate equation (1) on four different subsamples. Simply controlling for individuals' background characteristics, state- and time-fixed effects, and state average income and Medicaid enrollment may not eliminate the influence of omitted factors on the DDD estimate of the effect of the 
extension of Medicare. This could be true if the level of development of high-disability states changed in a way that was not fully captured by average income. It could also be true if the insurance coverage of individuals with a particular characteristic changed across states and over time due to some factor other than the extension of Medicare. African-Americans (due to the expanded enforcement of civil rights laws) or veterans (due to the changes in policy or practice after the Vietnam war), for example, may have been disproportionately represented in high-disability states and enjoyed expanded access to jobs or insurance over this period for reasons having nothing to do with Medicare. Finally, it could be true if the characteristics of heads of household in 1980 changed in some other, unobservable way from the characteristics in 1969-72 in a way that was correlated with insurance coverage and state disability rates.

Table 5 presents results from these analyses. Each column of the Table reestimates the model underlying column (2), Table 4, on a differently-restricted subsample. The first column of the Table omits all residents of Southern states (using the Census bureau's definition of the South: DE, DC, FL, GA, MD, NC, SC, VA, WV, AL, KY, MS, TN, AR, LA, OK, and TX). The point estimate of the effect of interest rises (although is certainly within two standard deviations of the effect in column (2), Table 4). Column (2) omits African-Americans, and column (3) omits veterans. The magnitude of the effect of interest declines slightly in these specifications, but is still statistically significant and indistinguishable from the effect on the full sample. Column (4) takes advantage of the panel nature of the PSID and restricts the sample to only those individuals who were head of a respondent household in 1980 and at least one of the years before the extension of Medicare (1969-72). Estimates from this sample hardly 
change at all, indicating that changes in unobserved differences across individuals is unlikely to be driving the results. 


\section{THE EFFECTS OF THE EXTENSION OF MEDICARE ON THE COMPREHENSIVENESS OF COVERAGE}

Nevertheless, it is still possible that our results could be generated by an unobserved process that is correlated with both changes in private insurance coverage rates and changes in disability rates across states. To further investigate this concern, we test whether differences in trends in disability rates across states affect the comprehensiveness of private insurance, as economic theory suggests that it should. If the extension of Medicare to the disabled increased private insurance coverage rates by increasing the extent of pooling, then it should have increased the scope of coverage as well.

To investigate whether this was so, we use data from the Health Insurance Council from 1970-1980. We construct a measure of the comprehensiveness of coverage in state $j$ at year $t, Q_{j t}$, equal to the number of people with coverage for hospital and general medical expenses divided by the number who were reported to have had coverage for hospital expenses. Early health insurance policies offered only coverage for hospital stays, but over the 1970s, policies began to include a wider range of services. We specify $Q_{j t}$ as a function of state fixed effects, $\alpha_{j}$, and time fixed effects, $\theta_{t}$; state Medicaid enrollment rates, $M_{j t}$; hospital insurance coverage rates $C_{j t}$; a variable capturing the state's SSDI enrollment rate, $D_{j t}$; interactions between $D_{j t}$ and indicator variable(s) for periods after the extension of Medicare; and a state-year error term $\varepsilon_{j t}$ :

$$
Q_{j t}=\alpha_{j}+\theta_{t}+\delta M_{j t}+\beta C_{j t}+\pi_{1} D_{j t}+\pi_{2}\left(D_{j t} * I_{t}(t \geq 1973)\right)+\varepsilon_{j t}
$$

and

$$
Q_{j t}=\alpha_{j}+\theta_{t}+\delta M_{j t}+\beta C_{j t}+\pi_{1} D_{j t}+
$$




$$
\pi_{2}\left(D_{j t} * I_{t}(1975 \geq t \geq 1973)\right)+\pi_{3}\left(D_{j t} * I_{t}(t \geq 1976)\right)+\varepsilon_{j t}
$$

and

$$
Q_{j t}=\alpha_{j}+\theta_{t}+\delta M_{j t}+\beta C_{j t}+\pi_{1} D_{j t}+\pi_{2}\left(D_{j t} * I_{t}(t \geq 1976)\right)+\varepsilon_{j t}
$$

Each of these specifications makes a slightly different assumption about the timing of the effect of interest. Model (2a) assumes that private insurance markets responded immediately to Medicare's coverage of the disabled. Models (2b) and (2c) assume that markets responded with a lag. Model (2b) estimates both the short-run and long-run effects, whereas model (2c) constrains the short-run effect to be zero.

Table 6 presents estimates from these models. The table shows that the comprehensiveness of private coverage expanded more in response to Medicare in states that had large disabled populations than in states that did not. Depending on specification, the share of hospital insurance policies that also provided medical expense coverage grew between 2.5 and 4.4 percentage points more in high-disability states. Descriptive statistics not presented in any table show that this effect was due to comprehensiveness starting lower in high-disability states, but catching up coincident with the extension of Medicare. In 1970, the proportion of hospital insurance policies that provided medical expense coverage was 75.9 percent in high-disability states and 84.7 percent in low-disability states. In 1973 , the proportions were 82.5 and 86.5 percent; by 1980, the proportions had become almost identical, at 89.5 and 90.6 percent. 


\section{CONCLUSIONS AND DIRECTIONS FOR FUTURE RESEARCH}

Using an important policy natural experiment, we have estimated the extent to which subsidies to cover high-cost individuals affect insurance coverage of others. According to our point estimates, extension of Medicare to an additional 0.5 percent of the population through the Social Security Disability Insurance program led to an increase in private insurance coverage of between 7.8 and 13.3 percentage points among individuals who described themselves as limited in the kind or amount of work that they can do. In 1980, these work-limited individuals were 15.7 percent of the total population. Thus, extending Medicare to an additional 0.5 percentage points of the population increased total insurance coverage by $1.2(=0.157 * 7.8)$ to $2.1(=0.157 * 13.3)$ percentage points. Subtracting off the 0.5 points due to the direct effect of the program gives a range for the spillover effect of $0.7(=1.2-0.5)$ to $1.6(=2.1-0.5)$ percentage points.

Our results can be used to calculate the marginal "target efficiency" of extending Medicare to the disabled in the 1970s. Gruber (2003), for example, suggests evaluating such programs in terms of a "bang for the buck" — the total government spending per dollar of insurance cost covered (that is, the cost per newly insured weighted by the cost of those who are gaining insurance). Medicaid expansions to low-income adults, according to Gruber, have a budget cost of $\$ 1.30$ per dollar of previously uncovered health costs. The budget cost exceeds $\$ 1.00$ because of crowding-out of private coverage; for every $\$ 1.00$ the government spends to newly insure someone with Medicaid, it must also give insurance to some number of individuals who would have had private coverage. 
Using the midpoint of our range of estimates of the extent of crowding-in of the non-disabled population of 1.15 percentage points $(1.15=((0.7+1.6) / 2))$ per 0.5 percentage points of Medicare expansion, the formula for the target efficiency of the program is:

$$
\left[0.5 c_{d}\right] /\left[1.15 c_{n}+(1-\lambda) * 0.5 c_{d}\right]
$$

where $\lambda$ is the extent of crowding-out of private insurance by Medicare; $c_{d}$ is the cost of public insurance for a newly covered disabled person; and $c_{n}$ is the cost of private insurance for a newly covered non-disabled person.

As the formula shows, one cannot calculate the target efficiency of the policy without information on extent of crowding-out of the program, the health spending of the newly covered disabled individuals, and the health spending of the newly covered nondisabled individuals. However, it is possible to calculate the conditions under which it is more target-efficient than a typical Medicaid expansion, ${ }^{4}$ or under which it achieves a target efficiency of less than one dollar per dollar of previously uncovered health costs -that is, no target efficiency cost. For example, assuming complete crowding-out of private insurance coverage $(\lambda=1)$ for the disabled, the target efficiency of the program reduces to $0.5 c_{d} / 1.15 c_{n}$. Thus, even with 100 percent crowd-out, the program is still more target-efficient than a typical Medicaid expansion, as long as $0.5 c_{d} / 1.15 c_{n}<1.3$, or $\left(c_{n} / c_{d}\right)>0.33$; the program has no target efficiency cost at all as long as $0.5 c_{d} / 1.15 c_{n}$ $<1$, or $\left(c_{n} / c_{d}\right)>0.43$. In 2003, Medicare reimbursed $\$ 6,471$ per disabled enrollee in the program, while the annual premium for a conventional, single-person employer-

\footnotetext{
${ }^{4}$ In principle, the coefficient from Table 4 on the number of Medicaid beneficiaries in a state could be used to assess the extent of Medicaid crowd-out. However, because states with low rates of private insurance coverage may (endogenously) expand their Medicaid programs, we instead use estimates of the target efficiency of Medicaid from other research.
} 
sponsored insurance policy was $\$ 3,576$ (Kaiser Family Foundation, Employer Health Benefits 2003 Survey), yielding an estimate of $\left(c_{n} / c_{d}\right)$ of 0.553 . Hence, at recent values of $c_{n}$ and $c_{d}$, the program is highly target-efficient.

The extent to which our estimates of the effects of the extension of Medicare can be extrapolated to future targeted subsidies remains an open question. Although our point estimates are quite large, several factors suggest caution in applying them out-ofsample. First, our estimates are measured with considerable error: the lower 95\% confidence bound in most specifications is approximately half the size of the point estimate. In addition, the extension of Medicare to the disabled arguably removed the most seriously chronically ill from the private insurance pool, and removed them completely; the people who would be covered by most proposed policies are likely to be less costly over the long run than SSDI recipients, and are likely to be subsidized less than fully. Future work might seek to account for these differences and use these estimates to simulate the effects of programs that are similar but not identical to the extension of Social Security to the disabled. 
Figure 1: Trends in insurance coverage rates in high- versus low-disability states, respondents with and without a work limitation, heads of household Panel Study of Income Dynamics, 1969-1972 and 1980

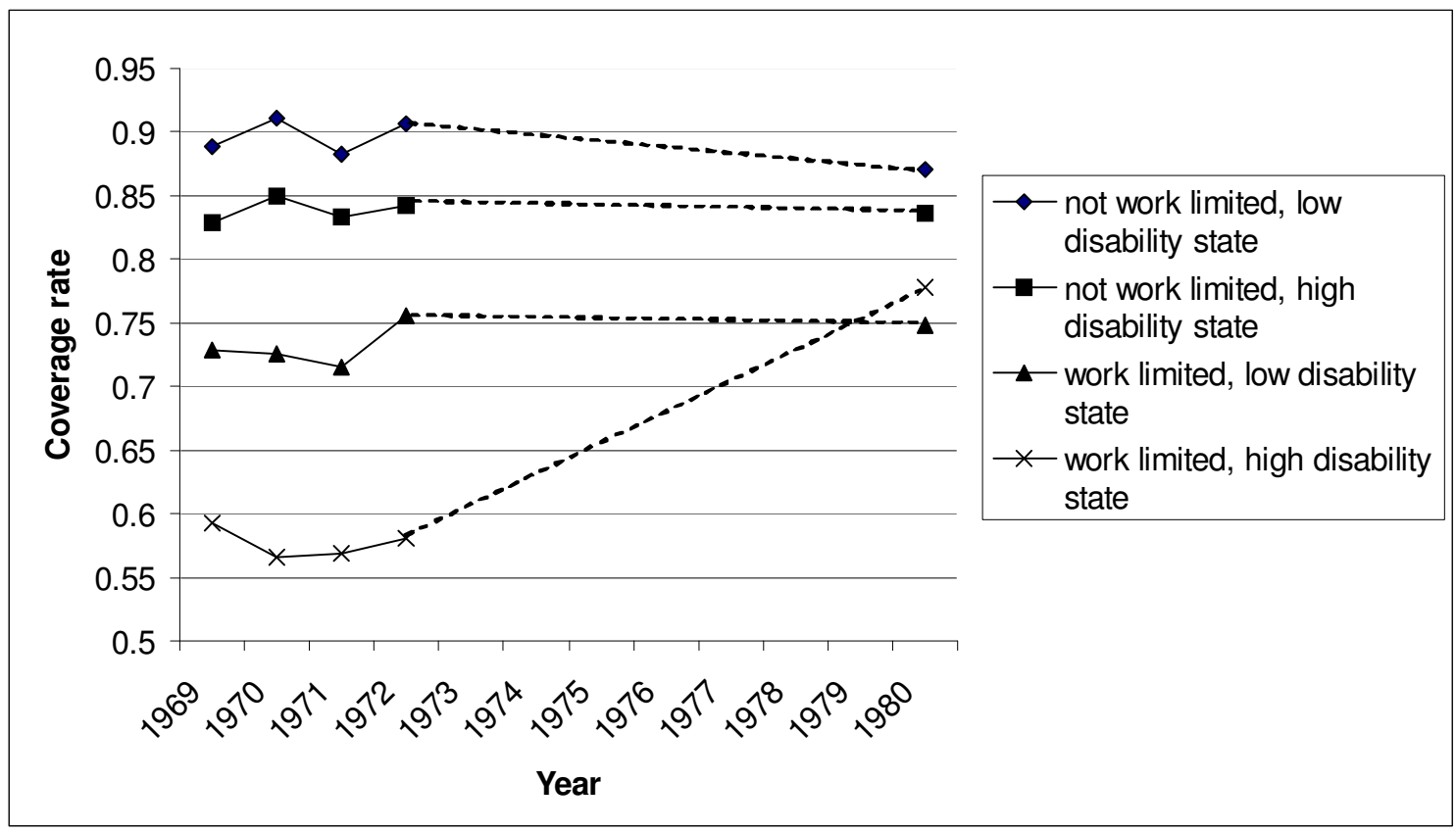


Table 1: Variables used in analysis, Panel Study of Income Dynamics, Heads of household, Means and (standard deviations)

$$
\text { 1969-1972 }
$$

Covered by insurance

Has condition limiting kind or amount of work

0.163

0.157

Family income $\$ 8,000$ - \$24,999 (1980\$)

0.511

0.486

Family income $>\$ 24,999(1980 \$)$

0.363

0.360

Professional/technical occupation

0.236

0.273

Self-employed

0.050

0.018

Not in labor force

0.117

0.152

High-school education

0.311

0.364

Some college

0.158

0.181

College or postgraduate degree

0.144

0.195

Female

0.204

0.244

Black

0.112

0.126

Veteran

0.391

0.311

Age

39.24

Family size

Medicaid/population in state of residence

State average income per capita (1980\$)

$\begin{array}{cc}8,813 & 10,058 \\ (1,313) & (1,258) \\ 16,747 & 5,655\end{array}$

$\mathrm{N}$

16,747

Notes: Reported statistics are calculated using PSID population weights. 
Table 2: States with high (above-median) disability rates

$\begin{array}{llll}1969 & 1970 & 1971 & 1972\end{array}$

$\begin{array}{lllll}\text { AL AR AZ } & \text { AL AR AZ } & \text { AL AR AZ } & \text { AL AR AZ } & \text { AL AR AZ } \\ \text { CA FL GA } & \text { CA DC FL } & \text { CA DC FL } & \text { CA DC FL } & \text { DE FL GA } \\ \text { KY LA ME } & \text { GA KY LA } & \text { GA KY LA } & \text { GA KY LA } & \text { KY LA ME } \\ \text { MO MS NC } & \text { ME MO MS } & \text { ME MO MS } & \text { ME MO MS } & \text { MO MS NC } \\ \text { OK OR PA } & \text { NC NY OK } & \text { NC NM OK } & \text { NC NM OK } & \text { NY OH OK } \\ \text { SC TN VA } & \text { OR PA SC } & \text { OR PA SC } & \text { OR PA SC } & \text { PA RI SC } \\ \text { WV } & \text { TN VA WV } & \text { TN VA VT } & \text { TN VA VT } & \text { TN VA WV } \\ & & \text { WV } & \text { WV } & \end{array}$

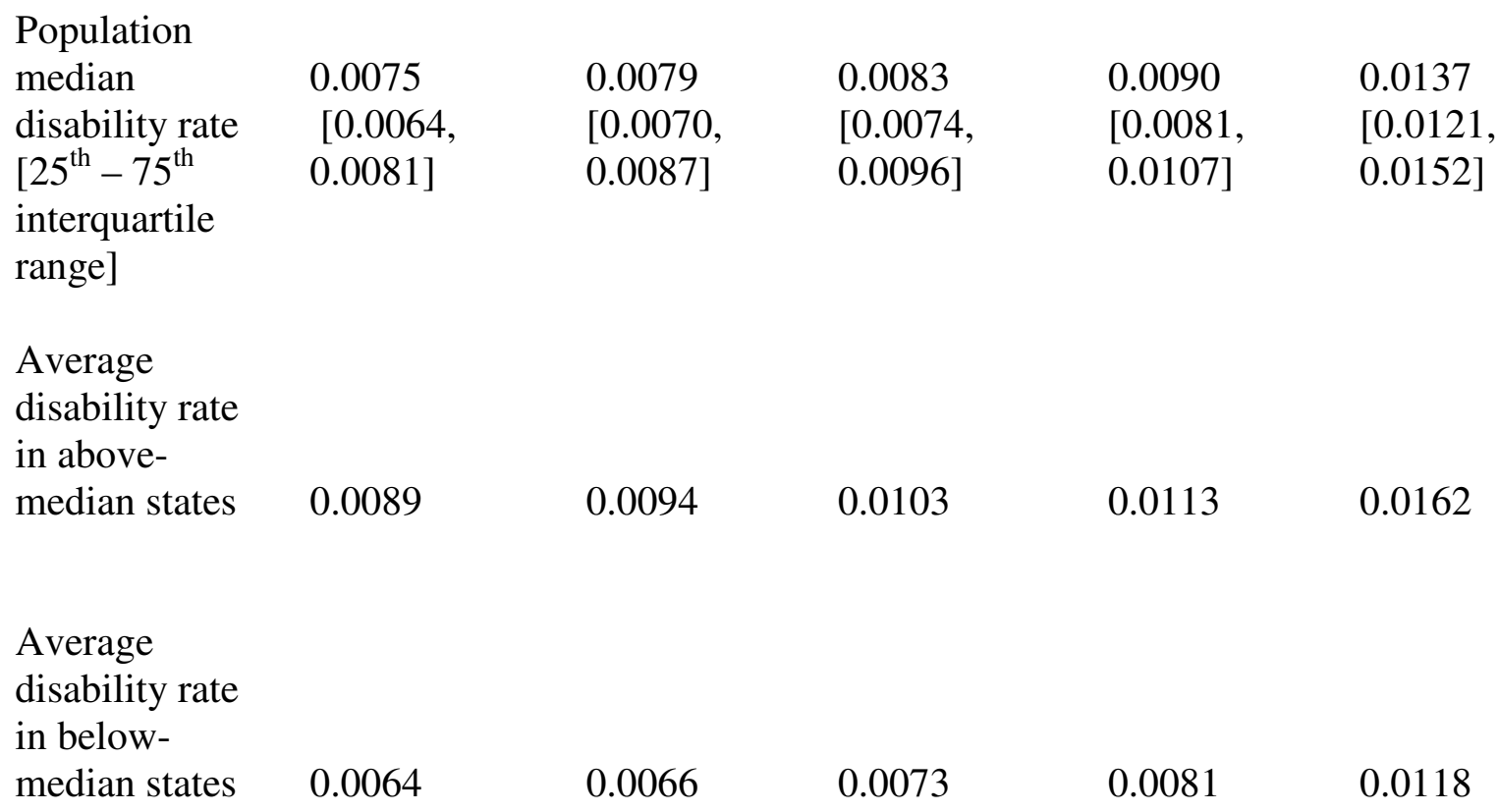

Note: Rates are calculated using PSID population weights. Source: Social Security Bulletin, Table Q-14, June 1970, December 1970-73, December 1981-82. 
Table 3: Average insurance coverage rates in high- versus low-disability states, respondents with and without a work limitation, heads of household Panel Study of Income Dynamics, 1969-1972 and 1980

\begin{tabular}{llllll} 
& High-disability states & \multicolumn{3}{c}{ Low-disability states } \\
Before & After & Percentage & Before & After & Percentage \\
Medicare & Medicare & point & Medicare & Medicare & point \\
extension & extension & change & extension & extension & change \\
$(1969-72)$ & $(1980)$ & & $(1969-72)$ & $(1980)$ &
\end{tabular}

\section{DD effect of Medicare extension After-Before extension, high- low disability states}

$\underline{\text { Respondents who are not work-limited }}$

$\begin{array}{lll}0.839 & 0.836 & -0.003 \\ & & (0.015)\end{array}$

0.897

0.871

$-0.026$

$(0.018)$

0.023

$(0.027)$

$\underline{\text { Respondents who are work-limited }}$

$\begin{array}{ccc}0.577 & 0.779 & 0.202 \\ & & (0.025)\end{array}$

0.731

0.748

0.017

0.185

(0.033)

$(0.045)$

DDD effect of Medicare Extension

0.162

Difference in work-limited versus not work-limited

(0.036)

After-Before extension, high-low disability states

Note: Heteroscedasticity-consistent standard errors allowing for within-state correlation are in parentheses. Estimates are calculated using PSID sample weights. $\mathrm{N}=22,402$, and the number of states (and number of clusters) is 50 . 
Table 4: The effect on insurance coverage rates of extending Medicare to the disabled, Panel Study of Income Dynamics, 1969-72 and 1980

(1)

Dependent variable $=1$ if has insurance coverage

\begin{tabular}{|c|c|c|}
\hline $\begin{array}{l}\text { Work-limited* } \\
\text { high-disability state*1980 }\end{array}$ & $\begin{array}{l}0.164^{* * *} \\
(0.037)\end{array}$ & $\begin{array}{l}0.133^{* *} \\
(0.036)\end{array}$ \\
\hline \multicolumn{3}{|l|}{$\begin{array}{l}\text { Work-limited } \\
\text { state disability rate* } 1980\end{array}$} \\
\hline \multicolumn{3}{|l|}{ Lower-level interaction terms } \\
\hline High-disability state ${ }^{*} 1980$ & $\begin{array}{r}-0.018 \\
(0.024)\end{array}$ & $\begin{array}{r}-0.017 \\
(0.023)\end{array}$ \\
\hline High-disability state ${ }^{*}$ work-limited & $\begin{array}{l}-0.089 * * * \\
(0.029)\end{array}$ & $\begin{array}{l}-0.050 * * \\
(0.022)\end{array}$ \\
\hline High-disability state & $\begin{array}{r}0.000 \\
(0.020)\end{array}$ & $\begin{array}{r}0.015 \\
(0.020)\end{array}$ \\
\hline
\end{tabular}

State disability rate*1980

$-1.377$

$-6.015$

(5.106)

(5.391)

State disability rate* work-limited

$-17.849^{* * *}$

-9.282 **

(5.415)

(3.690)

State disability rate

$-4.649$

10.775

(8.054)

(10.194)

Work-limited $^{*} 1980$

0.044

$0.080^{* * *}$

$-0.089$

$-0.022$

(0.031)

(0.028)

(0.098)

(0.087)

Work-limited

$-0.165^{* * *}$

$-0.057^{* * *}$

$-0.059$

$-0.003$

$(0.025)$

(0.016)

(0.053)

(0.035)

State Medicaid/pop rate

$-0.509 * * *$

-0.262 *

$-0.493^{* * *}$

-0.269 *

(0.154)

$(0.156)$

(0.139)

(0.152)

In regression but not reported in table

State, year FE State, year FE Individual controls State average income

Note: Individual controls include age 25-34, age 35-44, age 45-54, age 55-64 (omitted group is age 18-24); family income $\$ 8,000-\$ 24,999$, family income $>\$ 24,000$ (omitted group is family income $<\$ 8,000$ ); high-school education, some college, college or more (omitted group is less than high school); professional/technical occupation; selfemployment status; out of the labor force status; Black (race); female; veteran status; and family size. Also see note to Table 3. 
Table 5: The effect on insurance coverage rates of extending Medicare to the disabled, Panel Study of Income Dynamics, 1969-72 and 1980, alternative samples

(1)

\begin{tabular}{|c|c|c|c|c|}
\hline $\begin{array}{l}\text { Effect of Medicare extension } \\
\text { Work-limited* } \\
\text { high-disability state* } 1980\end{array}$ & $\begin{array}{l}0.1966^{* * *} \\
(0.040)\end{array}$ & $\begin{array}{l}0.123^{* * *} \\
(0.042)\end{array}$ & $\begin{array}{c}0.109 \text { * } \\
(0.057)\end{array}$ & $\begin{array}{l}0.131 \\
(0.043)\end{array}$ \\
\hline \multicolumn{5}{|l|}{ Lower-level interaction terms } \\
\hline High-disability state*1980 & $\begin{array}{r}-0.017 \\
(0.020)\end{array}$ & $\begin{array}{r}-0.020 \\
(0.023)\end{array}$ & $\begin{array}{r}-0.025 \\
(0.030)\end{array}$ & $\begin{array}{r}-0.023 \\
(0.018)\end{array}$ \\
\hline High-disability state*work-limited & $\begin{array}{l}-0.063 \text { ** } \\
(0.025)\end{array}$ & $\begin{array}{l}-0.052 \text { ** } \\
(0.025)\end{array}$ & $\begin{array}{l}-0.055 \text { * } \\
(0.031)\end{array}$ & $\begin{array}{l}-0.0666^{* *} \\
(0.025)\end{array}$ \\
\hline High-disability state & $\begin{array}{r}0.018 \\
(0.021)\end{array}$ & $\begin{array}{r}0.019 \\
(0.021)\end{array}$ & $\begin{array}{r}0.007 \\
(0.021)\end{array}$ & $\begin{array}{l}0.028 * \\
(0.016)\end{array}$ \\
\hline Work-limited*1980 & $\begin{array}{l}0.083^{* * *} \\
(0.030)\end{array}$ & $\begin{array}{l}0.0822^{* * *} \\
(0.031)\end{array}$ & $\begin{array}{r}0.083 \text { * } \\
(0.043)\end{array}$ & $\begin{array}{l}0.091 \\
(0.031)\end{array}$ \\
\hline Work-limited & $\begin{array}{l}-0.0522^{* \star *} \\
(0.019)\end{array}$ & $\begin{array}{l}-0.049^{* \star *} \\
(0.019)\end{array}$ & $\begin{array}{l}-0.057 \text { ** } \\
(0.024)\end{array}$ & $\begin{array}{l}-0.039 \text { ** } \\
(0.018)\end{array}$ \\
\hline State Medicaid/pop rate & $\begin{array}{r}-0.204 \\
(0.152)\end{array}$ & $\begin{array}{l}-0.260 \text { * } \\
(0.152)\end{array}$ & $\begin{array}{r}-0.095 \\
(0.220)\end{array}$ & $\begin{array}{l}-0.320 \text { ** } \\
(0.141)\end{array}$ \\
\hline $\begin{array}{l}\text { Excep } \\
\text { of South }\end{array}$ & $\begin{array}{l}\text { esidents } \\
\text { n states }\end{array}$ & $\begin{array}{l}\text { Except } \\
\text { Blacks }\end{array}$ & $\begin{array}{r}\text { Except } \\
\text { Veterans } \\
\text { an }\end{array}$ & $\begin{array}{l}\text { Individuals in } \\
\text { panel in } 1980 \\
\text { nd at least one } \\
\text { year, 1969-72 }\end{array}$ \\
\hline $\mathrm{N}$ & 12,931 & 13,999 & 15,527 & 14,706 \\
\hline
\end{tabular}

Effect of Medicare extension

Work-limited
high-disability state

Lower-level interaction terms

High-disability state* 1980

Dependent variable $=1$ if has insurance coverage

(2)

(3)

(4) 
Table 6: The effect on the comprehensiveness of health insurance of extending Medicare to the disabled, 1970-1980

Dependent variable:

Proportion of those with hospital insurance who have medical expense coverage

Effect of Medicare extension

(2)

(3)

(4)

(5)

(6)

High-disability state* 1973 or later

High-disability state* 1973-1975

High-disability state* 1976 or later

Lower-level interaction terms

High-disability state

Population weights?
0.035 *

$(0.020)$
0.013

(0.023)

$\begin{array}{crrrrr} & 0.022 & & & -0.004 & \\ & (0.017) & & & (0.023) & \\ & & & & & \\ & 0.044^{*} & 0.032 * & & 0.025 & 0.028 \text { * } \\ & (0.024) & (0.017) & & (0.025) & (0.016) \\ & & & & & \\ -0.017 & -0.018 & -0.008 & -0.003 & -0.003 & -0.005 \\ (0.019) & (0.019) & (0.015) & (0.019) & (0.019) & (0.016)\end{array}$

No

No

No

Yes

Yes

Yes

Note: Heteroscedasticity-consistent standard errors allowing for within-state correlation are in parentheses. All estimates control for state fixed effects, year fixed effects, State Medicaid/pop rate, and state hospital insurance rate. $\mathrm{N}=561$, and the number of states (and number of clusters) is 51 (includes DC). 


\section{References}

Bertrand, Marianne, Esther Duflo, and Sendhil Mullainathan, 2004, How much should we trust differences-in-differences estimates, Quarterly Journal of Economics 119(1): 249-275.

Gruber, Jonathan, 2003, Evaluating alternative approaches to incremental health insurance expansions, American Economic Review 93(2): 271-276.

Holahan, John, et al., 2003, A new approach to risk-spreading via coverage-expansion subsidies, American Economic Review 93(2): 277-282.

Newhouse, Joseph, 1996, Reimbursing Health Plans and Health Providers: Efficiency in Production Versus Selection, Journal of Economic Literature 34: 1236-63.

Rothschild, Michael, and Joseph Stiglitz, 1976, Equilibrium in Competitive Insurance Markets: An Essay on the Economics of Imperfect Information, Quarterly Journal of Economics 90(4): 629-49.

Swartz, Katherine, 2003, Reinsuring risk to increase access to health insurance, American Economic Review 93(2): 283-287. 